\title{
Analysis of Some Major Limitations of Analytical Top-Down Wind-Farm Models
}

\section{Stefan Emeis ${ }^{1}$}

Received: 9 August 2021 / Accepted: 8 December 2021

(c) The Author(s) 2022

\begin{abstract}
Analytical top-down and bottom-up wind-farm models have become major tools for quick assessment of yields from larger wind farms and the extension and properties of their wakes and have proven their principal applicability from recently obtained in situ observations. We review some of the limitations of top-down wind-farm models, partly in light of basic atmospheric boundary-layer findings which have been coined by the late Sergej Zilitinkevich. Essentially, for the applicability of such analytical models, the wind-farm turbine hub height should be small compared to the atmospheric boundary-layer height, and very small compared to the horizontal extension of the farm and the distance to the nearest surface inhomogeneities. Possibilities and options to include recently discovered blockage effects are also discussed.
\end{abstract}

Keywords Analytical model · Boundary-layer meteorology · Wind farms · Wakes · Zilitinkevich

\section{Introduction}

Analytical wind-farm models are attractive because they offer rapid answers much faster than numerical models. In this way, they are indispensable tools for first estimations and assessments on newly planned wind farms. Primarily, they give numbers for farm efficiency, and some of them also for the farm wake length, depending on installed power density, turbine thrust coefficients, surface characteristics, and atmospheric parameters. These models are based on long-standing basic laws of the atmospheric boundary layer, i.e., surface-layer similarity, Rossby number similarity, the logarithmic wind profile, and the geostrophic resistance law (Businger et al. 1971; Dyer 1974; Zilitinkevich 1975).

Two variants of analytical wind-farm models have been derived in the past: bottom-up models starting off from the description of a single wind-turbine wake (Jensen 1983) and then superposing multiple wakes, and top-down models regarding wind farms as one entity dissipating momentum, which is delivered from the sides and the layers above the farm (Bossanyi et al. 1980). A recent summary of the contemporary development of various

Stefan Emeis

stefan.emeis@kit.edu

1 Institute of Meteorology and Climate Research, Karlsruhe Institute of Technology, 82467 Garmisch-Partenkirchen, Germany 
bottom-up models (also often called engineering models) is given in Stieren and Stevens (2021). Examples of recent versions of top-down models are EFFWAKE (EFFWAKE is the name now assigned to the analytical model described in Emeis 2010 and Emeis 2018) and the model by Antonini and Caldeira (2021). The former considers thermal stability of the boundary layer in a non-rotating framework while the latter considers the Coriolis force in a neutral boundary layer. Only the first model gives an estimation of the farm-wake length as well. A general overview on wind-farm flows can be found in Porté-Agel et al. (2020).

Top-down models are an ideal tool to estimate the upper limit of extractable energy by large wind farms as well. This upper limit, which is relevant in designing sustainable global energy supply systems and in regional climate assessments, only depends on the ability of the atmosphere to produce kinetic energy from differential heating and to transport this kinetic energy downwards to the surface where wind farms are located. A very simple approach is given in Miller et al. (2015), and a more detailed three-layer approach (wind-farm layer, windfarm canopy layer, and outer layer) can be found in Luzzatto-Fegiz and Caulfield (2018). Recently, Klaidon (2021) reviewed this not-yet-finally-solved issue. Numerical flow models which address the same topic are outside the scope of this paper. For recent achievements with numerical models see, e.g., Akhtar et al. (2021).

Although such top-down models are very simple, recent comparisons (Cañadillas et al. 2020; Platis et al. 2021a) have shown an astonishing overall agreement with respect to wind-farm efficiency and wind-farm wake length between EFFWAKE results and the first available in situ measurements over and behind larger offshore wind farms in the North Sea from aircraft within the framework of the WIPAFF (WInd PArk Far Field) experiment (Lampert et al. 2020; Platis et al. 2020).

Above-mentioned agreements have to be considered together with a longer list of limitations for top-down models. Without claiming to be complete, the list of assumptions comprises:

(1) indefinitely large wind farms,

(2) stationarity,

(3) horizontal homogeneity,

(4) wind turbines are small compared to the height of the boundary layer,

(5) governing equations from different boundary-layer descriptions fit together,

(6) vertical turbulent momentum flux is shear-driven only.

The purpose of this paper is to discuss these limitations and to assess the applicability of top-down wind farm models given the steady growth of wind turbines themselves and the size of wind farms. Simultaneously, this paper intends to cast a spotlight on an appealing encounter where long-standing very basic theoretical laws of the atmospheric boundary layer meet urgently wanted applications in a growing industrial issue.

\section{A Short Model History and Characterization}

Top-down approaches consider the wind farm either as an additional surface roughness or as an additional momentum sink at hub height that modifies the mean boundary-layer flow and turbulence. The first one-layer approach by Bossanyi et al. (1980) for the reduction of the wind speed in a large wind farm assumed a wind-speed-dependent turbine drag and a logarithmic layer, in which the wind farm is fully immersed and which also accounts for the momentum replenishment from above. Frandsen (1992) derived a two-layer model for the wind-speed reduction in the centre of a large wind farm by assuming a logarithmic wind profile below 
hub height and the validity of the resistance law developed by Zilitinkevich (1975) above hub height. The germ for the EFFWAKE model was then created when Emeis and Frandsen (1993) reformulated the Frandsen (1992) model without making specific assumptions on the wind profiles in the two layers below and above hub height. The price paid for this simplification and generalization is the necessity to specify a length-scale ratio between the height difference between hub height and the height of the flow above which is undisturbed by the wind farm, $\Delta z$, and the mixing length, $l$. Emeis and Frandsen (1993) set this ratio as

$$
\frac{\Delta z}{l}=\frac{2}{\kappa} \approx 5
$$

where $\kappa=0.4$ is the von Kármán constant. Rooijmans (2004) then took the Emeis and Frandsen (1993) model, made it stability dependent by stipulating

$$
\frac{\Delta z}{l}=\frac{\phi_{m}+2}{\kappa}
$$

using the dimensionless shear $\phi_{m}$ (Businger et al. 1971; Dyer 1974), and compared it to MM5 simulations (MM5 version 3.5, Dudhia et al. 2000), finding reasonable agreement.

Triggered by Rooijmans' (2004) comparison, Emeis (2010) revised the Emeis and Frandsen (1993) model by not only using (2) but by also making the relation for the drag exerted by the surface underneath the wind farm stability dependent using the usual relations from surface-layer similarity theory. This was not included by Rooijmans (2004). In addition, an estimation of the length of the farm wake was added based on the same approach that momentum has to be replenished by turbulent motion from above. Finally, Emeis (2018) added turbine-induced turbulence to the Emeis (2010) model. This 2018 model version is now labelled EFFWAKE (Fig. 1). The large-scale forces in Fig. 1 are mainly the pressure gradient force and the Coriolis force (Antonini and Caldeira 2021).
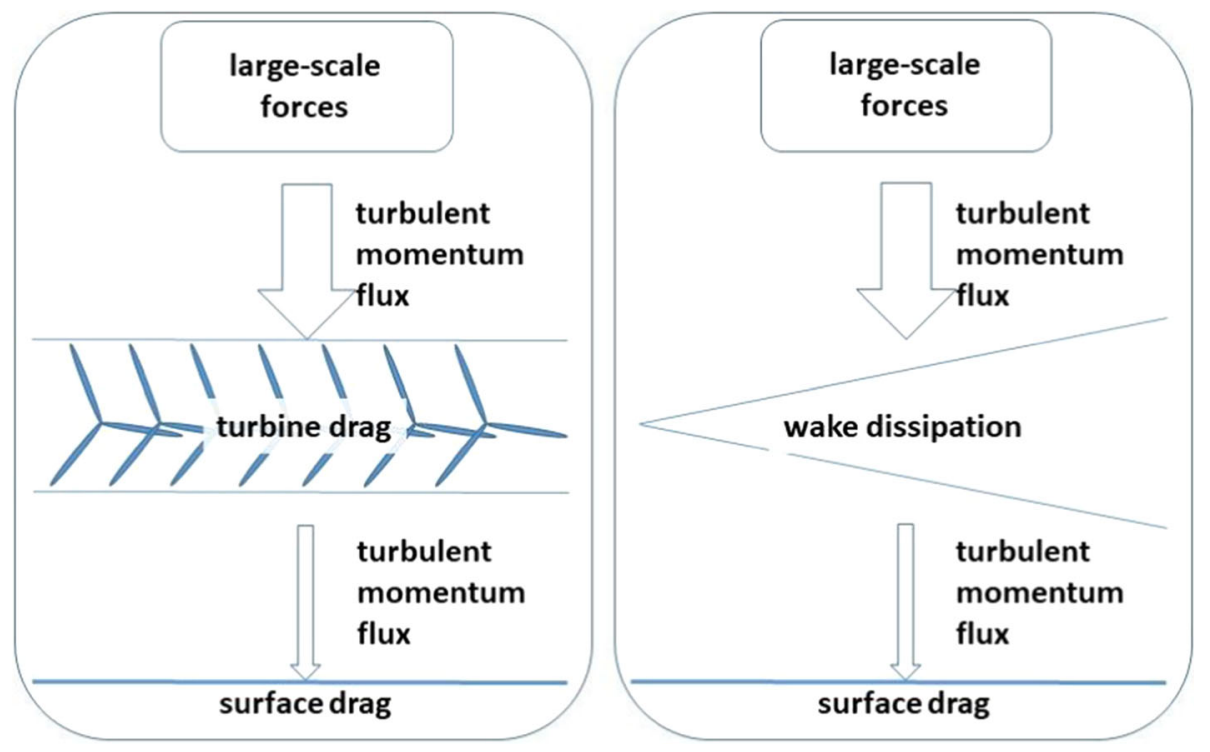

Fig. 1 Schematic side view of the EFFWAKE model. Left: vertical fluxes and forces for the estimation of the farm efficiency, right: vertical fluxes and forces for the estimation of the wake length implying a flow from the left 
The introduction of the turbine-induced turbulence required a reformulation of that part of the model which contained the mixing length. Now, the unspecified length-scale ratio $r_{l s}$ in the model formulation turns out to be the ratio

$$
r_{l s}=\frac{h+\Delta z}{\Delta z} \approx 2,
$$

where $h$ is the hub height of the turbines. This ratio is held constant in the EFFWAKE model, but it could be that it is stability dependent in the same way as (2). The constancy of this ratio (3) is also discussed in Platis et al. (2020), and some variation with stability from measured data is documented. The final equation for the reduced wind speed at hub height $R_{t}$ in an indefinitely large wind farm in the EFFWAKE model reads

$$
R_{t}=\frac{\left(\frac{\phi_{m} c_{s, h}}{\kappa^{2}}+r_{l s} I_{\text {ueff }}\right)}{\left(\frac{\phi_{m} c_{\text {teff }}}{\kappa^{2}}+r_{l s} I_{\text {ueff }}\right)},
$$

where $c_{s, h}$ is the stability-dependent surface drag felt at hub height $h, c_{t e f f}$ is the sum of surface drag and turbine drag, and $I_{\text {ueff }}$ is the turbulence intensity including the turbulence induced by the presence of the operating turbines. The ratio $R_{t}$ is less than unity and strongly depends on atmospheric stability. It takes the smallest value for strongly stable conditions, because then the vertical turbulent momentum fluxes governing the replenishment of momentum are smallest. This fits to the experimental results presented in Platis et al. (2021a) who showed values of $R_{t}$ of about 0.6 for stable conditions. Equation 4 demonstrates that the ability of the atmosphere to replenish the momentum extracted by the turbines is the limiting factor for the yield of large wind farms and not the exact number and layout of the turbines within the farm. For the assessment of the reduction of power obtainable from an indefinitely large wind farm we have to consider the third power of (4).

Recovery of wind speed in the wake $R_{w}$ turns out to be an exponential function in the EFFWAKE model

$$
R_{w}(t)=\frac{u_{h w}(t)}{u_{0}}=1+\left(R_{t}-1\right) \exp (-\alpha t)
$$

where $u_{h w}$ is wind speed at hub height in the wake and $u_{0}$ is the undisturbed wind speed at hub height upstream of the wind farm. The factor governing the exponential function in (5), $\alpha=\kappa u_{*} h / \Delta z^{2}$ with the friction velocity $u_{*}$, is the stability-dependent and surfaceroughness-dependent recovery coefficient ( $u_{*}$ depends on these two properties). Due to the appearance of $\Delta z$ in this expression it is subject to the same constancy discussions as with reference to (3) above. Using $u_{h w}$, this time domain result can be translated into the spatial domain. The value of $R_{w}$ is less than unity but approaches unity with increasing distance from the leeward wind farm edge. For the recovery of the available power in the wake we have once again to take the third power of (5). Wake length is specified as the distance behind the farm where $95 \%$ of the undisturbed value is reached again. The full derivation of (4) and (5) can be found in Emeis (2018).

Flow features in a wind-farm wake should in principle have something in common with those in the lee of a forest canopy (Liu et al. 1996; Träumner et al. 2012), which is different from a pure flow transition over a roughness change from rough to smooth. But porosity of a wind turbine canopy is much larger than the porosity of a forest canopy so that no recirculation is found in the lee of wind farms. Actually, porosity is not a factor in analytical wind farm models. Only drag forces at the surface and at hub height reduce the atmospheric flow speed. 


\section{Assessment of the Limitations}

The basic boundary-layer laws mentioned at the beginning of the introduction are simple, notwithstanding that the knowledge on the atmospheric boundary layer has increased dramatically over the last 50 years (this is more or less exactly the time span within which the late Sergej Zilitinkevich performed his scientific work). A very recent summary on the knowledge on the atmospheric boundary layer is given by Helbig et al. (2021). Here the six limitations listed in the Introduction are discussed in more detail.

\subsection{Assumption of Indefinitely Large Wind Farms}

The EFFWAKE model and other top-down models assume that a wind farm extends more or less indefinitely, i.e., the ratio $l_{x y} / h$ tends to infinity, where $l_{x y}$ is the characteristic horizontal extension of the wind farm. This implies that lateral momentum fluxes into the wind farm are negligible and that no outer zone of the farm is regarded where single wake effects are still relevant. This assumption simplifies the balance of forces considerably: the extraction of momentum by the turbines is completely balanced by the downward turbulent momentum flux in the atmospheric layer above hub height. In the EFFWAKE model a predetermined undisturbed wind speed at hub height or a predetermined geostrophic wind speed is considered as an unlimited momentum source and the downward turbulent momentum flux is the limiting factor. Antonini and Caldeira (2021) predetermine a pressure gradient force and a latitudedependent Coriolis force as limiting factors. Klaidon (2021) even goes a step further and predetermines the ability of the atmosphere to produce kinetic energy from heat differences and sets this ability as an upper limit for the large-scale energy generation from the wind.

It is difficult to assess from which size onwards real wind farms can be regarded as indefinitely large. The occurrence of deep-array wake effects (Barthelmie and Jensen 2010) may be a good indicator for this. Usually, depending on the angle between wind direction and the orientation of turbine rows, five to ten rows of turbines are sufficient that the single turbine wakes start to merge to a common farm wake (see Fig. 2). When such a merger takes place, simple superposition strategies should no longer work, because single wakes no

\begin{tabular}{|c|c|c|c|c|c|c|c|c|c|c|c|}
\hline 1 & $I$ & 1 & 1 & I & I & I & I & I & I & I & I \\
\hline 1 & 1 & 1 & I & 1 & I & 1 & 1 & I & I & I & I \\
\hline 1 & $\mathrm{I}$ & 1 & 1 & 1 & 1 & 1 & 1 & 1 & I & 1 & I \\
\hline 1 & 1 & 1 & 1 & 1 & 1 & 1 & 1 & I & 1 & 1 & I \\
\hline 1 & $I$ & 1 & I & I & I & I & I & I & I & I & I \\
\hline 1 & $I$ & $I$ & I & I & I & I & I & I & I & 1 & I \\
\hline 1 & 1 & I & I & I & I & I & I & I & I & I & I \\
\hline
\end{tabular}

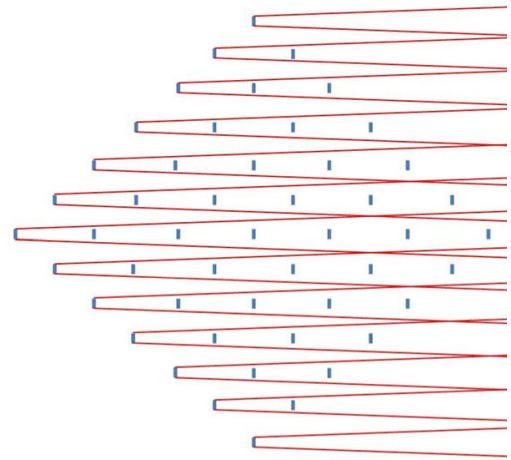

Fig. 2 Schematic of deep-array effects in a rectangular wind farm. Left: incident flow direction is parallel to the turbine rows of the wind farm. Right: incident wind is $45^{\circ}$ off the direction of the turbine rows. Little blue bars symbolize wind turbines with rotor diameter $D$, red lines mark outer boundaries of wakes of upwind turbines. Longitudinal and lateral distances between turbines: $5 D$. A wake decay coefficient of 0.04 is assumed (Jensen 1983) 
longer have lateral outer boundaries through which momentum could entrain into the wake laterally. The above-mentioned experimental validations of the EFFWAKE model (Platis et al. 2020; Cañadillas et al. 2020) used data behind wind farms with eight to ten rows of turbines. Thus, seven to eight rows of turbines seem to be sufficient to apply a top-down model for estimating the farm efficiency in the farm interior and the wake length, i.e., the onset of deep-array effects seems to be a good indicator for the validity of the application of a top-down wind-farm model.

\subsection{Assumption of Stationarity}

Analytical wind-farm models have been formulated by stipulating a stationary balance between extracting and supplying forces. Thus, they do not work properly for non-stationary conditions, neither for developing synoptic weather situations nor for diurnal variations over land. Both time scales are related to the rotational time period of the Earth, $f^{-1}$, with $f$ being the Coriolis parameter. This means that analytical models work best for time scales larger than

$f^{-1}$. But over land they should also be shorter than half a day which is roughly $\pi f^{-1}$. Therefore, for example, they cannot simulate bending wakes, which are often observed behind real offshore wind farms. This has to be kept in mind when comparing analytical model simulations with experimental data. Nevertheless, the impact of slowly evolving weather situations on large offshore wind farms can be approximated by a sequence of analytical farm model solutions initialized independently from each other with varying large-scale outer conditions.

\subsection{Assumption of Horizontal Homogeneity}

Analytical wind-farm models do not work properly in cases of horizontal inhomogeneity such as coast lines and internal boundary layers caused by such inhomogeneity, because there is only one downward momentum flux in the model, which is representative for the entire wind farm. This implies that $d / l_{x y}$ should be large, with $d$ being the distance to an upstream coast line or any other significant surface property change.

For the same reason, different farm layouts cannot be modelled with a top-down model. The only farm parameter known in the model is the overall drag exerted by the turbines. In the EFFWAKE model, this drag is computed from the number of turbines per unit area and the wind-speed-dependent thrust coefficient. This latter point is also the reason why the solution of a top-down model is wind direction independent. Wind-direction can only be considered indirectly by specifying different atmospheric stability for the simulations. Hence, typical weather patterns linked to different wind directions in a given area can be represented with a top-down model. This allows for, e.g., the construction of a farm-efficiency distribution or a wake-length distribution as function of atmospheric stability (an example of a wake-length distribution is shown in Emeis 2018), if a stability distribution as presented in Platis et al. (2021b), for example, is known. 


\subsection{Assumption on Turbine Height to Boundary-Layer Height Ratio}

Top-down models make assumptions on the wind profile or at least on the surface drag (geostrophic drag law, Zilitinkevich 1975). This implies that the wind turbines are small compared with the height of the boundary layer, $z_{i}\left(h / z_{i}<1\right)$, or even to the height of the surface layer, $z_{P}\left(h / z_{P}<1\right)$ when the validity of the logarithmic wind profile is assumed for the layer above the turbines as well. This assumption was fulfilled to a large extent when these analytical models were developed for the first time 30-40 years ago, because at that time wind turbines were only up to a few tens of metres high.

The drag law also has some limitations in itself. For strong stable stratification, the geostrophic drag coefficient becomes independent of the surface friction, see (13) in Emeis and Zilitinkevich (1991). But also for not so extremely stable stratification the height of the stable boundary layer becomes so small (see, e.g., Zilitinkevich and Baklanov 2002) that the turbines extend above the stable-boundary-layer height.

For nearly neutral stratification the increase of the surface drag coefficient including the drag of the wind turbines is limited to about twice the pure surface drag coefficient, because otherwise the square root in the geostrophic drag law becomes imaginary (see (6) in Emeis and Zilitinkevich 1991). This limitation disappears for strongly unstable situations.

\subsection{Assumption on Fitting Together Different Wind-Profile Descriptions}

Surface-layer-similarity theories give height-dependent relations for wind speed (Businger et al. 1971; Dyer 1974); Ekman-based theories do so as well, but geostrophic drag laws (Zilitinkevich 1975) do not. The derivation of seamless vertical wind profiles has been investigated at least during the last two decades (see, e.g., fitting approaches for Prandtl and Ekman layer wind profiles in Etling 2002, Emeis et al. 2007, Gryning et al. 2007, and Peña et al. 2010). All these approaches need additional length scales, which are not easily at hand. The height of the Prandtl layer is needed for the matching of a surface-layer profile with an Ekman-layer profile in Etling (2002) and Emeis et al. (2007), or different forms of modified mixing lengths are needed in Gryning et al. (2007) and Peña et al. (2010) in order to create seamless profile descriptions. Although analytical wind-farm models do not explicitly use these rather complicated seamless vertical profiles, they do rely on the principal possibility of matching surface-layer relations below hub height with Ekman layer relations or the geostrophic drag law above hub height when formulating the equilibrium relation for wind speed at hub height. This does not circumvent the necessity for an additional length scale. The open (and thus tunable) ratios (1) to (3) given above demonstrate that such a length scale-in this case the height difference $\Delta z$-is missing for this profile matching in the analytical models. Returning to one-layer solutions such as in Bossanyi et al. (1980) is no longer an option, because modern wind turbines extend over at least two layers.

\subsection{Assumption on Turbulence Generation}

Generally, the friction velocity is linked to vertical wind shear when closing the full set of equations of motion. This means that vertical profile laws and also the geostrophic drag law, which involve the friction velocity, are based on the presence and dominance of sheardriven turbulence, which in turn is responsible for vertical turbulent momentum fluxes. This assumption leads to problems in strongly stable conditions where well-defined turbulence is 
no longer present (see Sect. 3.4 above), and in strongly unstable conditions where thermally driven turbulence dominates the shear-driven turbulence (see, e.g., Stull 1988).

\subsection{Resumé of the Assumption Assessment}

The above given assessment can be summarized by the statement that analytical top-down wind-farm models work best when the hub height, $h$, of the turbines in the wind farm follows relations with the boundary-layer height, $z_{i}$, the horizontal farm length scale, $l_{x y}$, and the distance, $d$, to the next upstream surface inhomogeneity as given in (6),

$$
h<z_{i} \text { and } h \ll l_{x y}<d,
$$

and when the considered time scale is larger than $f^{-1}$ (but smaller than $\pi f^{-1}$ for onshore wind farms) and the predominant turbulence responsible for turbulent momentum fluxes is shear-generated.

\section{Additional Limitations: Global Blockage}

The main purpose of analytical top-down wind-farm models is to estimate the annual energy production of larger wind farms by computing the overall power efficiency of such larger farms. A currently emerging second purpose is the estimation of wake effects (Platis et al. 2020), which is becoming increasingly important for the design and operation of larger clusters of wind farms in regions with limited areal resources. Layout issues within single wind farms have to be dealt with by using bottom-up analytical wind farm models as long as those farms are not too large and the nonlinear deep-array effects (Barthelmie and Jensen 2010) do not dominate the output parameters.

Likewise, farm efficiency and wake effects have been the focus of experimental studies so far. This applies to the first in situ aircraft experiment around North Sea offshore wind farms (Platis et al. 2020) as well. But there are also blockage effects (also known as induction zones or upstream wakes) of single turbines and turbines in larger wind farms, which have entered the discussion recently, and which are neither fully understood nor even covered in analytical models. Blockage effects related to the entire upstream edge of wind farms are also known as global blockage effects. Engineering standards (IEC 2005) still assume that flow reduction upstream is limited to two rotor diameters so that the upstream wind speed between two and four rotor diameters upstream could be considered as undisturbed (Segalini and Dahlberg 2019). Medici et al. (2011) present wind-tunnel data which show that the upstream blockage effect can be detected to more than three rotor diameters, and that the wind-speed reduction at two rotor diameters upstream is between 2 and $5 \%$. Bleeg et al. (2018) found from several experimental studies that the average wind-speed reduction two rotor diameters upstream is about $3.4 \%$, and according to this source, the reduction at seven to ten rotor diameters upstream is still $1.9 \%$. Global blockage is dependent on atmospheric stratification. From lidar measurements the largest blockage effect is found with stable stratification while the effect is vanishing within normal wind fluctuations with strong unstable conditions (Schneemann et al. 2021). Thus, global blockage is not a negligible effect and should be included in analytical wind-farm models.

The first attempts in including bottom-up models are described in Bleeg et al. (2018), Nygaard et al. (2020), and Forsting et al. (2021). A first comparison of such inclusions with a large-eddy simulation is described in Centurelli et al. (2021). This comparison shows that 
bottom-up models have some difficulties in simulating global blockage since this blockage seems to involve nonlinear interactions with the atmospheric boundary layer (e.g., those interactions described in Smith 2010 and Allaerts and Meyers 2017) not included in bottomup models.

Inclusion of blockage effects in top-down models such as EFFWAKE is not known to the author so far. Given the construction principle of top-down models, which defines the overall drag exerted by the turbines of a wind farm by the number of these turbines multiplied by the wind-speed-dependent thrust coefficient, an inclusion of the blockage effect can only be done by introducing additional dependencies of the turbine thrust coefficient, i.e., making it also stratification-dependent and mean turbine distance-dependent. This task definitely needs more data on blockage effects than is presently available. In particular, the part of global blockage related to nonlinear interactions with the atmospheric boundary layer and not with the electrical energy generation (Smith 2010; Allaerts and Meyers 2017; Centurelli et al. 2021) has to be analyzed more deeply before designing approaches which mirror global blockage in top-down models.

\section{Short Application Example}

Here, a demonstration of a possible application of a top-down model (here EFFWAKE) in the framework of future planning of offshore wind farms in the German part of the North Sea is given. The example foresees 100 turbines with a rated power of $15 \mathrm{MW}$ per turbine at $11 \mathrm{~m} \mathrm{~s}^{-1}$ wind speed to be deployed over an area of $150 \mathrm{~km}^{2}$. This corresponds to an areal density of installed power of $10 \mathrm{MW} \mathrm{km}{ }^{-2}$. The assumed roughness of the sea surface is $0.0001 \mathrm{~m}$. The cut-in wind speed is $3 \mathrm{~m} \mathrm{~s}^{-1}$ and the cut-out wind speed is $25 \mathrm{~m} \mathrm{~s}^{-1}$. The interval between these two wind speeds is divided into 22 wind speed bins with a constant bin width of $1 \mathrm{~m} \mathrm{~s}^{-1}$. The EFFWAKE model is run 22 times with pre-described undisturbed wind speeds representing the centres of the chosen wind speed bins. The frequency by which these wind speed bins occurs is specified from a given wind statistic (extracted from the New European Wind Atlas; Hahmann et al. 2020; Dörenkämper et al. 2020), and the power curve of a hypothetical $15 \mathrm{MW}$ wind turbine with hub height of $150 \mathrm{~m}$ and rotor diameter of $240 \mathrm{~m}$ is applied.

Taking the EFFWAKE results for neutral thermal stratification, farm efficiency starts at 0.57 for low wind speeds and increases to unity for incident wind speeds of $15.5 \mathrm{~m} \mathrm{~s}^{-1}$ and above. This leads to an overall efficiency of this wind farm of 0.80 (this efficiency compares the total output of a wind farm with a given number of wind turbines to the output of the same number of isolated wind turbines), 4361 full load hours, and an annual energy production of 6.542 TWh, i.e., on the average each turbine produces $0.065 \mathrm{TWh}$ per year. Repeating the calculation for a farm with 90 such turbines deployed to the same area (i.e., an areal density of installed power of $9 \mathrm{MW} \mathrm{km}^{-2}$ ) leads for neutral stability to a slightly higher overall farm efficiency of $0.81,4416$ full load hours, and an annual energy production of $5.961 \mathrm{TWh}$. This mean each turbine produces $0.066 \mathrm{TWh}$ per year on average. The reported efficiencies of 0.80 and 0.81 are lower bounds for very large farms with the specified density of installed power. Real farms with 90-100 turbines perform marginally better, because the turbines at the upwind edge are not subject to wakes. But larger farms with more turbines come closer to these values. The simulation could be made even more realistic if a thermal 
stability distribution is supplied for each wind-speed bin and the available respective nonneutral values are taken from the EFFWAKE simulations as well. Unfortunately, stability distributions were not available for the above example.

Computations such as those in the above example can be made to design optimum wind farms from energetic and economic constraints. The latter constraint comes in when a price per turbine is specified. In the above example, more energy per unit area is harvested in the $10 \mathrm{MW} \mathrm{km}^{-2}$ wind farm, whereas more energy per installed turbine is harvested in the $9 \mathrm{MW} \mathrm{km}{ }^{-2}$ wind farm. As the overall German annual net electricity generation (https:// energy-charts.info) is in the order of $500 \mathrm{TWh}$, this means that, hypothetically, roughly 80 to 85 such offshore power plants would meet this generation demand, if appropriate energy storage devices were available. A further discussion of a secure energy supply is beyond the scope of this paper.

\section{Conclusion}

Notwithstanding the above discussed simplifications, assumptions, and deficiencies, analytical wind-farm models remain 'first-assessment' tools in the wind energy industry, as they do not need much computer resources. For deeper analyses they have to be followed by more detailed simulations with scale-interacting computational wind engineering models, computational fluid dynamics models, or mesoscale meteorological models (see, e.g., Emeis 2015). Inclusion of recently detected important influencing processes on the annual estimated production of wind turbines and wind farms such as global blockage (Sect. 4) remains a challenge and will —if successful — help to keep these first-assessment tools up to date. The inclusion of global-blockage effects also requires a scientific analysis of whether and how deep-array effects and global-blockage effects overlap. This last issue does not seem to have been addressed in the literature so far.

The basic similarity theories for the atmospheric boundary layer derived by Sergej Zilitinkevich and his contemporaries have us brought very far, even in fields of direct application. The analytical models used in wind energy meteorology today are a very good example for this.

\section{Tribute to Sergej Zilitinkevich}

The author is happy to have had the opportunity of extensive discussions with the late Sergej Zilitinkevich in 1990 and 1991. Sergej Zilitinkevich visited the Institute of Meteorology and Climate Research of the then Technical University of Karlsruhe in 1990 where the author was working as a post doc on numerically simulating form drag exerted by orographic features on the atmospheric boundary layer (Emeis 1987, 1990). The boundary-layer expertise of Sergej Zilitinkevich very much supported the description of this form drag in terms of internal and external boundary-layer parameters.

The second fruitful encounter with Sergej Zilitinkevich happened during a stay of the author at the Wind Energy Institute of the then Ris $\varnothing$ National Laboratory near Roskilde, Denmark. It was at this stay in Denmark when the author first got in contact with wind energy meteorology and the very first ideas of the EFFWAKE model emerged from parallel discussions with the late Sten Frandsen of Ris $\varnothing$ National Laboratory and Sergej Zilitinkevich. 
The primary outcomes of these discussions are documented in Emeis and Zilitinkevich (1991) and Emeis and Frandsen (1993).

Acknowledgements I would like to thank the Guest Editors of this Special Issue, Dmitrii Mironov, Andrey Grachev, and Alexander Baklanov, for the personal invitation to submit this paper. The WIPAFF experiment was funded by the German Ministry of Economic Affairs and Energy under grant 0325783 following a decision of the Deutsche Bundestag.

Funding Open Access funding enabled and organized by Projekt DEAL.

Open Access This article is licensed under a Creative Commons Attribution 4.0 International License, which permits use, sharing, adaptation, distribution and reproduction in any medium or format, as long as you give appropriate credit to the original author(s) and the source, provide a link to the Creative Commons licence, and indicate if changes were made. The images or other third party material in this article are included in the article's Creative Commons licence, unless indicated otherwise in a credit line to the material. If material is not included in the article's Creative Commons licence and your intended use is not permitted by statutory regulation or exceeds the permitted use, you will need to obtain permission directly from the copyright holder. To view a copy of this licence, visit http://creativecommons.org/licenses/by/4.0/.

\section{References}

Akhtar N, Geyer B, Rockel B, Sommer PS, Schrum C (2021) Accelerating deployment of offshore wind energy alter wind climate and reduce future power generation potentials. Sci Rep 11:11826

Allaerts D, Meyers J (2017) Boundary-layer development and gravity waves in conventionally neutral wind farms. J Fluid Mech 814:95-130

Antonini EGA, Caldeira K (2021) Atmospheric pressure gradients and Coriolis forces provide geophysical limits to power density of large wind farms. Appl Energy 281:116048

Barthelmie RJ, Jensen LE (2010) Evaluation of wind farm efficiency and wind turbine wakes at the Nysted offshore wind farm. Wind Energy 13:573-586

Bleeg J, Purcell M, Ruisi R, Traiger E (2018) Wind farm blockage and the consequences of neglecting its impact on energy production. Energies 11:1609

Bossanyi EA, Maclean C, Whittle GE, Dunn PD, Lipman NH, Musgrove PJ (1980) The efficiency of wind turbine clusters. In: Proceedings of the 3rd international symposium on wind energy systems, Lyngby (DK), August 26-29, pp 401-416

Businger JA, Wyngaard JC, Izumi Y, Bradley EF (1971) Flux profile relationships in the atmospheric surface layer. J Atmos Sci 28:181-189

Cañadillas B, Foreman R, Barth V, Siedersleben S, Lampert A, Platis A, Djath B, Schulz-Stellenfleth J, Bange J, Emeis S, Neumann T (2020) Offshore wind farm wake recovery: airborne measurements and its representation in engineering models. Wind Energy 23:1249-1265

Centurelli G, Vollmer L, Schmidt J, Dörenkämper M, Schröder M, Lukassen LJ, Peinke J (2021) Evaluating Global Blockage engineering parametrizations with LES. J Phys Conf Ser 1934:012021

Dörenkämper M, Olsen BT, Witha B, Hahmann AN, Davis NN, Barcons J, Ezber Y, García-Bustamante E, González-Rouco JF, Navarro J, Sastre-Marugán M, Sĩle T, Trei W, Žagar M, Badger J, Gottschall J, Sanz Rodrigo J, Mann J (2020) The Making of the New European Wind Atlas-part 2: production and evaluation. Geosci Model Dev 13:5079-5102

Dudhia, J, Gill D, Guo Y, Manning K, Michalakes J, Bourgois A, Wang W, Wilson J (2000) Mesoscale modelling system tutorial class notes and user's guide: MM5 modelling system version 3, PSU/NCAR

Dyer AJ (1974) A review of flux-profile relations. Boundary-Layer Meteorol 7:363-372

Emeis S (1987) Pressure drag and effective roughness length with neutral stratification. Boundary-Layer Meteorol 39:379-401

Emeis S (1990) Pressure drag of obstacles in the atmospheric boundary layer. J Appl Meteorol 29:461-476

Emeis S (2010) A simple analytical wind park model considering atmospheric stability. Wind Energy 13:459-469

Emeis S (2015) Observational techniques to assist the coupling of CWE/CFD models and meso-scale meteorological models. J Wind Eng Ind Aerodyn 144:24-30

Emeis S (2018) Wind energy meteorology, 2nd edn. Springer, Cham, pp 161-170 
Emeis S, Frandsen S (1993) Reduction of horizontal wind speed in a boundary layer with obstacles. BoundaryLayer Meteorol 64:297-305

Emeis S, Zilitinkevich SS (1991) Resistence law, effective roughness length, and deviation angle over hilly terrain. Boundary-Layer Meteorol 55:191-198

Emeis S, Baumann-Stanzer K, Piringer M, Kallistratova M, Kouznetsov R, Yushkov V (2007) Wind and turbulence in the urban boundary layer-analysis from acoustic remote sensing data and fit to analytical relations. Meteorol Z 16:393-406

Etling D (2002) Theoretische Meteorologie - Eine Einführung, 2nd edn. Springer, Berlin

Forsting AM, Rathmann OS, van der Laan MP, Troldborg N, Gribben B, Hawkes G, Branlard E (2021) Verification of induction zone models for wind farm annual energy production estimation. J Phys Conf Ser 1934:012023

Frandsen S (1992) On the wind speed reduction in the center of large clusters of wind turbines. J Wind Eng Ind Aerodyn 39:251-265

Gryning S-E, Batchvarova E, Brümmer B, Jørgensen H, Larsen S (2007) On the extension of the wind profile over homogeneous terrain beyond the surface layer. Boundary-Layer Meteorol 124:251-268

Hahmann AN, Sīle T, Witha B, Davis NN, Dörenkämper M, Ezber Y, García-Bustamante E, González-Rouco JF, Navarro J, Olsen BT, Söderberg S (2020) The making of the New European Wind Atlas-part 1: model sensitivity. Geosci Model Dev 13:5053-5078

Helbig M, Gerken T, Beamesderfer ER, Baldocchi DD, Banerjee T, Biraud SC, Brown WOJ, Brunsell NA, Burakowski EA, Burns SP, Butterworth BJ, Chan WS, Davis KJ, Desai AR, Fuentes JD, Hollinger DY, Kljun N, Mauder M, Novick KA, Perkins JM, Rahn DA, Rey-Sanchez C, Santanello JA, Scott RL, Seyednasrollah B, Stoy PC, Sullivan RC, Vilà-Guerau de Arellano J, Wharton S, Yi CX, Richardson AD (2021) Integrating continuous atmospheric boundary layer and tower-based flux measurements to advance understanding of land-atmosphere interactions. Agric For Meteorol 307:108509

IEC (2005) IEC 61400-12-1 wind turbines. Part 12-1: power performance measurements of electricity producing wind turbines. International Electrotechnical Commission, Geneva

Jensen NO (1983) A note on wind generator interaction. Ris $\emptyset-\mathrm{M}-2411$, Ris $\emptyset$ Natl. Lab., Roskilde (DK). http:// backend.orbit.dtu.dk/ws/portalfiles/portal/55857682/ris_m_2411.pdf. Accessed 28 Dec 2021

Klaidon A (2021) Physical limits of wind energy within the atmosphere and its use as renewable energy: from the theoretical basis to practical implications. Meteorol Z (Contrib Atmos Sci) 30:203-225

Lampert A, Baerfuss K, Platis A, Siedersleben S, Djath B, Canadillas B, Hunger R, Hankers R, Bitter M, Feuerle T, Schulz H, Rausch T, Angermann M, Schwithal A, Bange J, Schulz-Stellenfleth J, Neumann T, Emeis S (2020) In situ airborne measurements of atmospheric and sea surface parameters related to offshore wind parks in the German Bight. Earth Syst Sci Data 12:935-946

Liu J, Chen JM, Black TA, Novak MD (1996) E- $\varepsilon$ modelling of turbulent air flow downwind of a model forest edge. Boundary-Layer Meteorol 77:21-44

Luzzatto-Fegiz P, Caulfield CCP (2018) Entrainment model for fully-developed wind farms: effects of atmospheric stability and an ideal limit for wind farm performance. Phys Rev Fluids 3:093802

Medici D, Ivanell S, Dahlberg JÅ, Alfredsson PH (2011) The upstream flow of a wind turbine: blockage effect. Wind Energy 14:691-697

Miller LM, Brunsell NA, Mechem DB, Gans F, Monaghan AJ, Vautard R, Keith DW, Kleidon A (2015) Two methods for estimating limits to large-scale wind power generation. Proc Natl Acad Sci USA 112:11169-11174

Nygaard NG, Steen ST, Poulsen L, Pedersen JG (2020) Modelling cluster wakes and wind farm blockage. J Phys Conf Ser 1618:062072

Peña A, Gryning S-E, Mann J, Hasager CB (2010) Length scales of the neutral wind profile over homogeneous terrain. J Appl Meteor Climatol 49:792-806

Platis A, Bange J, Bärfuss K, Cañadillas B, Hundhausen M, Djath B, Lampert A, Schulz-Stellenfleth J, Siedersleben S, Neumann T, Emeis S (2020) Long-range modifications of the wind field by offshore wind parks - results of the project WIPAFF. Meteorol Z (Contrib Atmos Sci) 29:355-376

Platis A, Hundhausen M, Mauz M, Siedersleben S, Lampert A, Bärfuss K, Djath B, Schulz-Stellenfleth J, Canadillas B, Neumann T, Emeis S, Bange J (2021a) Evaluation of a simple analytical model for offshore wind farm wake recovery by in situ data and Weather Research and Forecasting simulations. Wind Energy 24:212-228

Platis A, Hundhausen M, Lampert A, Emeis S, Bange J (2021b) The role of atmospheric stability and turbulence in offshore wind farm wakes in the German bight. Boundary-Layer Meteorol. https://doi.org/10.1007/ s10546-021-00668-4

Porté-Agel F, Bastankhah M, Shamsoddin S (2020) Wind-turbine and wind-farm flows: a review. BoundaryLayer Meteorol 174:1-59 
Rooijmans P (2004) Impact of a large-scale offshore wind farm on meteorology: numerical simulations with a mesoscale circulation model. Master's thesis, Utrecht University. https://docs.wind-watch.org/ rooijmansmesoscale.pdf. Accessed 28 Dec 2021

Schneemann J, Theuer F, Rott A, Dörenkämper M, Kühn M (2021) Offshore wind farm global blockage measured with scanning lidar. Wind Energ Sci 6:521-538

Segalini A, Dahlberg J-Á (2019) Blockage effects in wind farms. Wind Energy 23:120-128

Smith RB (2010) Gravity wave effects on wind farm efficiency. Wind Energy 13:449-458

Stieren A, Stevens RJAM (2021) Evaluating wind farm wakes in large Eddy simulations and engineering models. J Phys Conf Ser 1934:012018

Stull R (1988) An introduction to boundary-layer meteorology. Kluwer Academic Publishers, Dordrecht

Träumner K, Wieser A, Ruck B, Frank C, Röhner L, Kottmeier C (2012) The suitability of Doppler lidar for characterizing the wind field above forest edges. Forestry 85:399-412

Zilitinkevich SS (1975) Resistance laws and prediction equations for the depth of the planetary boundary layer. J Atmos Sci 32:741-752

Zilitinkevich S, Baklanov A (2002) Calculation of the height of the stable boundary layer in practical applications. Boundary-Layer Meteorol 105:389-409

Publisher's Note Springer Nature remains neutral with regard to jurisdictional claims in published maps and institutional affiliations. 